\title{
النظام اللغوي في اللهجة العربية الأهوازيّة وهدى التأثّر باللغة الفصى واللهجات القديمة
}

\section{م. د. رسول بلأويs جامعة خليج فارسر/ ايراز}

إهتمّ الباحثون و علماء اللغة كثيراً باللهجات في العقود الأخيرة لإقتر ابها و إنتقاقها من اللغات الفصحي. و لا يخفى أنّ هذه

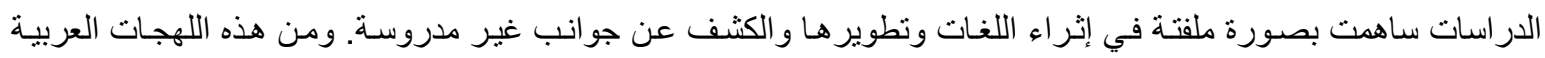

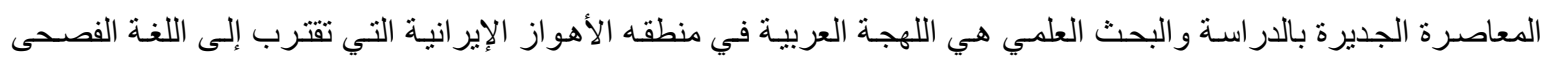

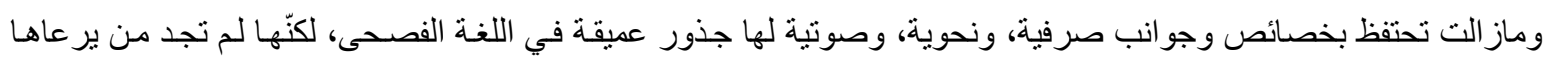

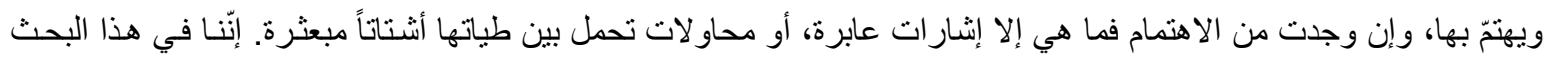

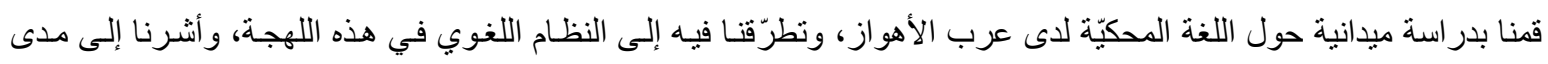

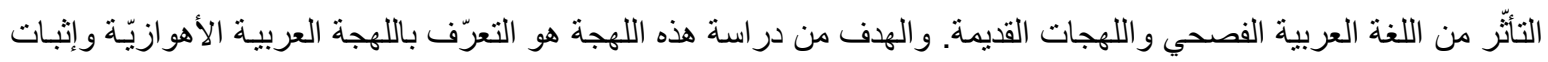

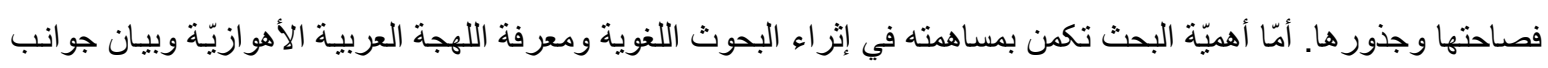
منها متجذّرة في اللغة الفصحى. الكلمات الليلية: النظام اللغوي؛ اللغة العربيّة؛ اللهجات العربية، الأهو از.

\section{الاقدهمة:}

إنّ در اسة اللهجات العربية الحديثة در اسة علمية في كل البيئات العربية، ومعرفة خو اصـها المميزة لها و وناطق توزيعها مطلب يجد الباحثون في حقل الدراسـات اللغويـة إلى تحقيقه، لمـا في ذلك من فائدة جليلة، فالكثف عن و اقع اللغة المعينة في المجتمع المعين، وتعرف مـا أصسابها من تغيير أو تنوع، ومظـاهر هذا أو

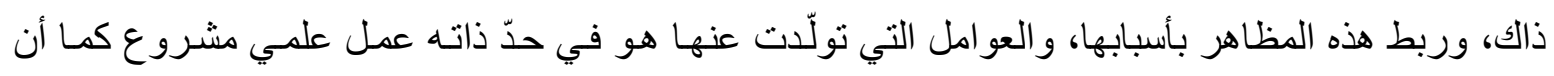
نتائج مثل هذه الدر اسة تضيء جو انب يكتنفها الظلام و الغموض في بعض اللهجات العربية القديمة، فضلاً عن الاستفادة منها في حركة الإصلاح اللغوي على مستوى اللغة النموذجية فدراسة اللهجات بطريقة علمية مدققة

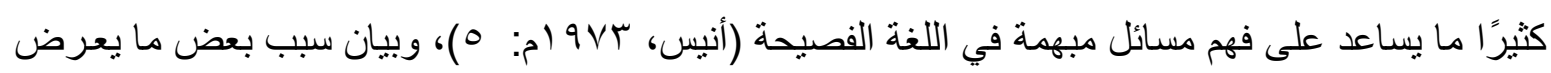
من الأمور المشكلة في صرفها ونحوها و ألفاظها. (بشر 990 (م: VV (1) وقد كانت در اسـات اللهجات المحلية

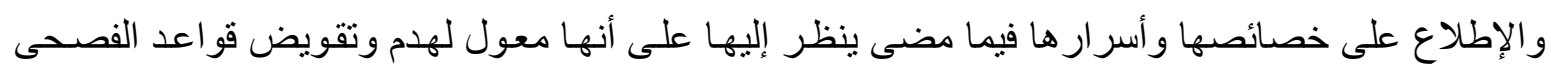

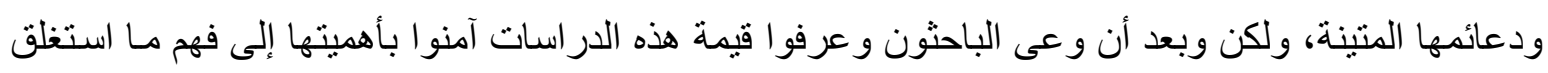
من أسرار وخفايا عديدة في الفصحى.

تتّجه الدر اسات اللغوية اليوم في كثير من الأمم الناهضـة، إلى تسجيل لهجاتها الحديثة، لأنها تمثل تطوراً تاريخياً تحرص الأمة على تسجيله قبل أن بصيبه تطور آخر ويندثر، و لا نتدهش أن يعكف كثثر من اللغويين في تلك الأمم على در اسـة اللهجات الحديثة دراسـة وصفية، فتر اهم يصفون أصـواتها وصفاً علمياً

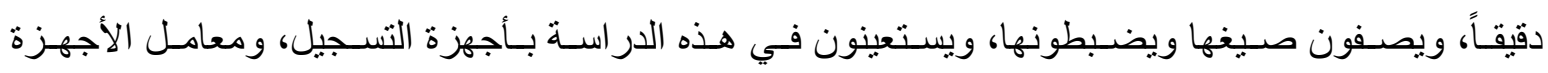

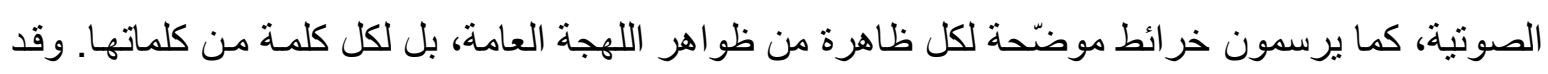

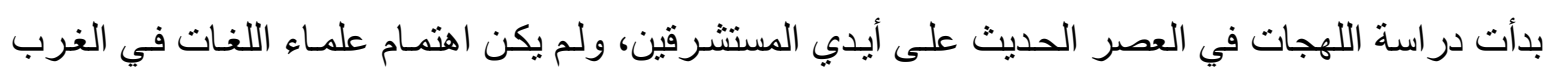


مقصورًا على اللهجات في الأقطار الأوروبية فحسب، بل كان للهجات العربية ـ قديمها وحديثها جانب كبير من اهتماماتهم.

وقد أخذت كثير من ظواهر اللهجة المحلية في التلاشي والانحسار شأنها شـأن اللهجات الأخرى، وهذا ما حدا بنـا إلى جمع هذه الأشتات خشية عليها من الاندثار. فقبل أن نتطرّق إلى دراسـة خصـائص اللهجـة الأهو ازية نقّم فذلكة تاريخية عن الإقليم وساكنيه. تعود هجرة القبائل العربية إلى الأهواز إلى مـا قبل ظهور الإسـلام بـأكثر مـن ألف عـام. فقد جـاء في كتب التـاريخ أن بعض القبائل العربيـة قد دخلت إيران في عهد داريوش الكبير(القرن السـادس قبل الـميلاد) وقد توغلت في جميع أنحاء الإمبر اطوريـة الإخمينيـة آنذاكهـ.

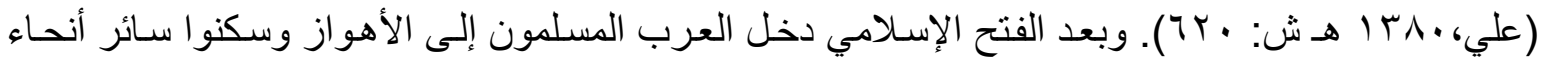

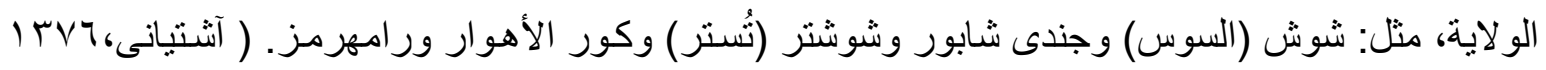

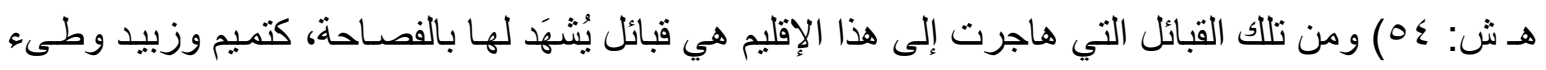
و أسد وربيعة و الأنصار و عُبادة وخفاجة، وأخلاف هذه القبائل اليوم يحتفظون بقدر غير قليل من الفصـاحة في

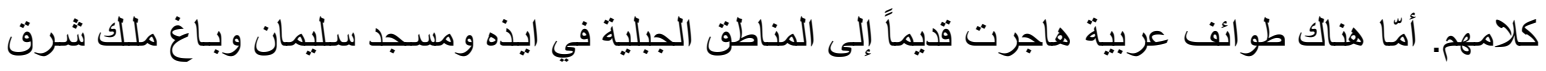
الأهو از، وفي دهلر ان وبدرة وآبدانان في محافظة ايلام، شمال غرب الأهواز، وفي هنديجان وبهبهان جنوب شرق الأهواز، تللك الطو ائف اختلطت مع السكان الأصليين حتى أنهم بعد أجيال نسو الهجتهم العربية وصساروا

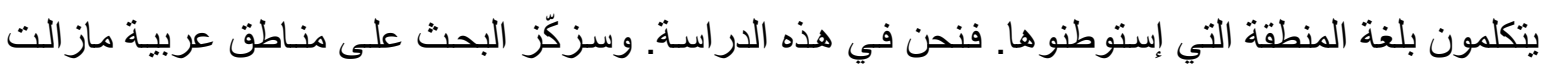
اللهجة العربية هي اللغة المحكيّة لدى سكانها. ومن أبرز هذه المدن التي ماز الت تتكلّم بالعربيـة هي مدينة الأهو از، و الحويزة، والبسيتين، و الخفاجية، والثوش، و عبادان، و المحمرة، و الفلاحيّة، و الحميديـه، و.. فسكّان هذه المدن العربية على اختلاف القبائل التي تقطن فيها تشترك في البُني الصرفية والنحويـة وتركيب الجمل؛ فإنّها تتفق في كل شيء ما عدا بعض الظواهر الصـونية، التي تتصل بنطق صوت معين، أو بوظيفة نطقيـة كالنبر، والإيقاع، وما زال هذا هو الأساس الذي نعرف به انتماء الناطق أمامنا إلى قبيلةٍ ما أو منطقة خاصة. إنّنا في هذه الدراسة سوف نتطرّق إلى دراسة النظـام اللغوي في اللهجـة العربيـة الأهوازيّة ومدى

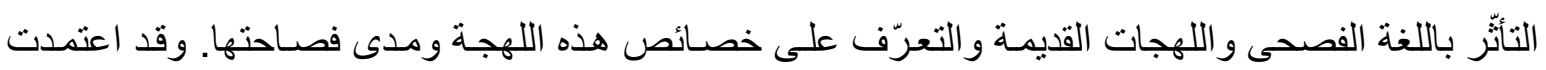
هذه الدر اسة على ثثلاثة مناهج:

أولاً، المنهج الوصفي: وهو وصف للظواهر اللهجيّة وتحديد خصائصها المتمثّلة بلغة التخاطب فيما بينهم. ثانياً، المنهج التحليلي: يعتمد على در اسة البنى الوظيفية وسياقاتها وطبيعة تركيبها. ثالثاً المنهج التقابلي التطبيقي: يعتمد على عرض قو اعد اللهجة المدروسـة اللغـة العربيـة الفصحى و اللهجات القديمة

\section{خلفية البحث}

كُتبت در اسات لا بأس بها حول اللهجات العربية القديمة والمعاصـرة في العالم العربي وفي مـا يلي نخص منها بالذكر: 》في اللهجـات العربيـة| لـ "إبر اهيم أنبس"؛ و لاللهجـات في التراثه لـ "أحمد الدين

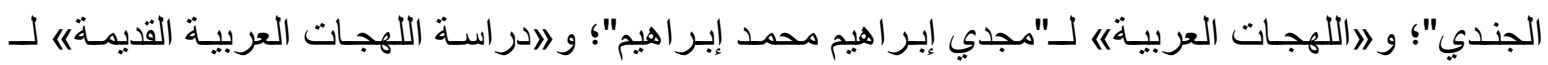


"داود سلوم"؛ و اللاهجات العربية في القراءات القر آنيةها لـ"عبده الراجحي"؛ و الهجـة البدو في إقليم سـاحل مريوط《 لـ"عبدالعزيز مطر".

أمـا الدراسـات التـي تناولت اللهجـة العربيـة الأهوازيّة في إيـران منهـا رسـالة ماجستير موسـومة بـاأصول جذور اللهجة العربية الأهوازيّة في اللغة العربيـة الفصحيه لـ"عاطي عبيات" في جامعـة الثــيد تشمر ان وقد تتاول الباحث في در استه جذور المفردات في اللغنة الفصحي؛ ورسـالتنا في مرحلة الماجستير تحت عنوان ابررسى سـاختار هاى دستورى (صـرفى - نحوى) در لهجهـ عربسى خوزستانه في الجامعـة

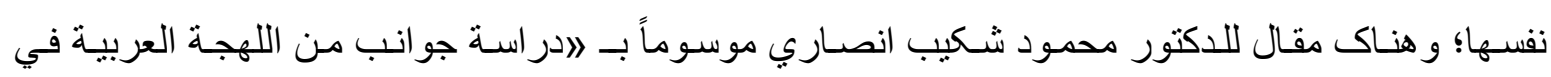
خوزستانه تمّ نشره في العدد الحادي عشر من هذه المجلة (أي مجلة العلوم الإنسـانية الدوليـة) وقد ركّز الباحث في در استه هذه على جوانب صرفية نتئنحوية من اللهجة.

اللهجة في اللغة هي طرف اللسـان أو جرس الكلام، ويقال فلان فصيح اللهجـة، وهي لغته التي جبل عليها، فاعنادهـا ونشأ عليها (ابن منظور، 971 (م: مـادة لهج). أما في الاصطلاح فتعني العـادات الكلامية

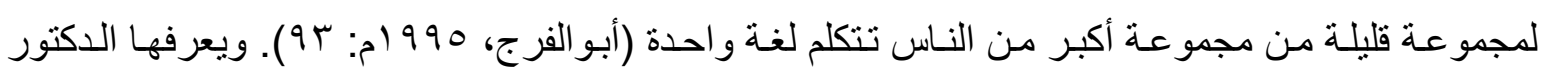
إبر اهيم أنبس بأنها لامجمو عـة من الصفات اللغويـة التي تتنمي إلى بيئة خاصـة، ويشترك في هذه الصفات

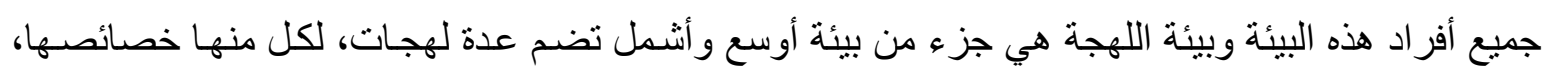
ولكنها تشترك جميعًا في مجموعة من المظاهر اللغوية التي تيسر اتصـال أفر اد هذه البيئات بعضهم ببعض، ونه

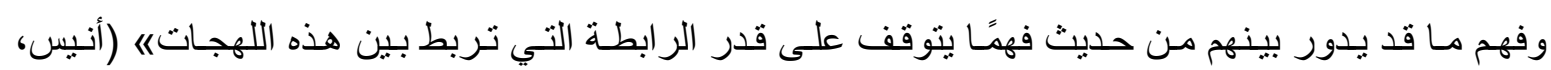

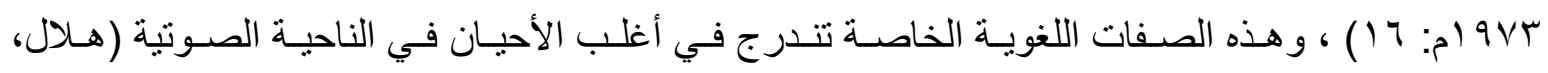

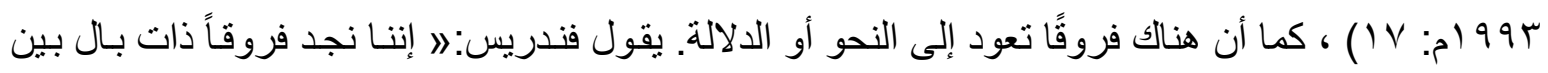

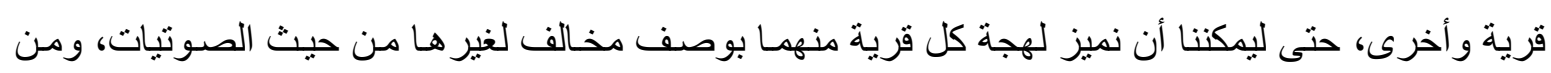

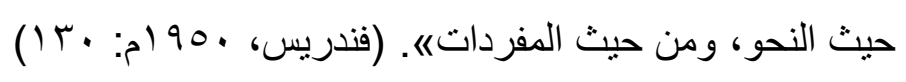

\section{ظاهرة الإبدال: - نإه}

الإبدال في اللغة هو قيام شيء مقام الثيء الذاهب، يقال بدلت الثـيء إذا غيرته و أن لم تـأت لـه ببدل، قال تعالى/قل ما يكون لي أن أبدله من تلقاء نفسيه يونس/ه 1، و البدل: خلق من السيء، و التبديل: التغيير،

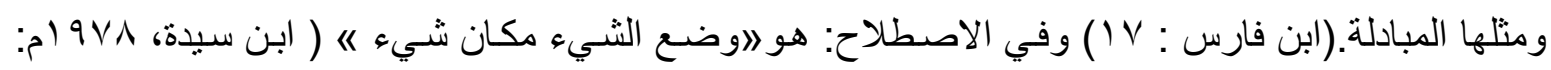

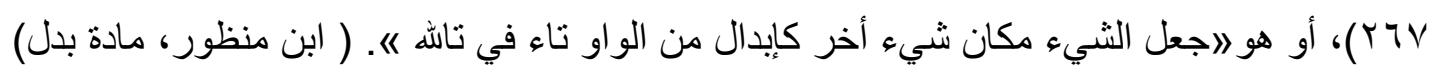
اللهجة العربية في الأهواز كسائر اللهجات العربية مارست الإبدال وخضعت لذوق جمهور ها في إبدال الحروف بعضها مقام البعض وفي ما يلي نشير إلى أهِّ ظوا هر هذا الإبدال:

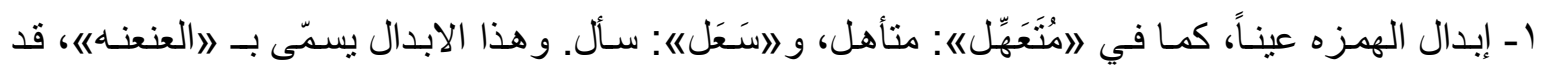

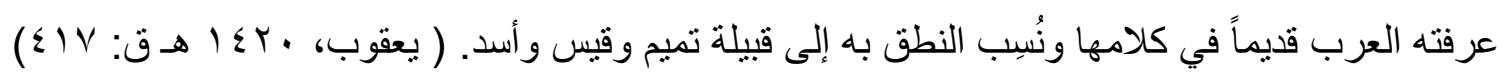


وسبب الابدال في هذه الظاهرة، تجاور المخرجين فالهمزة حنجرية مهموسة والعين حلقية مجهورة.

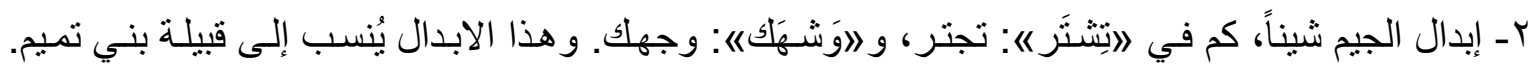

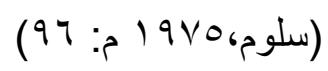

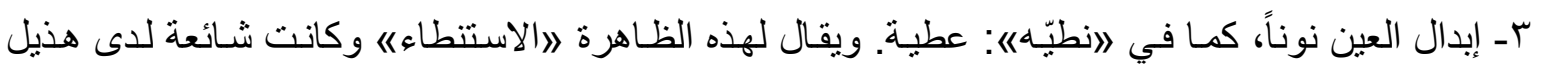

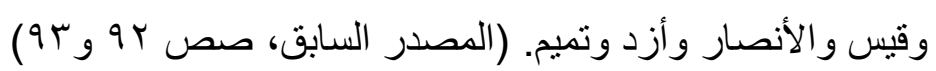

مصطلح (الاستنطاء) مشنق من مزيد الفعل (أنطى) الذي هو محور الظـاهرة. فالاستـنطاء في لغـة

سعد بن بكر وهذيل والأزد وقيس والأنصار تجعل العين السـاكنة نونـاً إذا جاورت الطساء كأنُطي في أعْطِي.

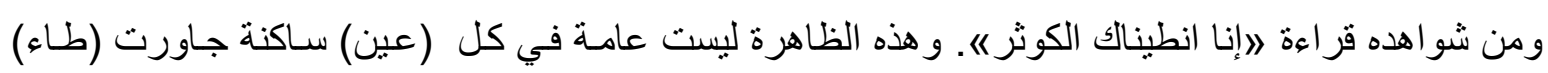
و إنما هو خاص بكلمة (أعطى) ومشتقاتها. وقلب (عين) إلى (طاء) ليس لـه تفسير صوتي لبعد مخرجيهما. وليس في وسعنا تفسير هذه الظاهرة بالإبدال، لأن شرط الإبدال هو القرابة الصوتية، وليس بين العين و النون

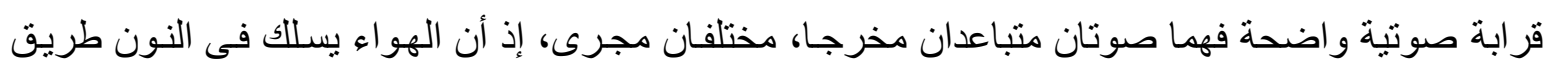
الأنف، ويسلك فى العين طريق الفم.

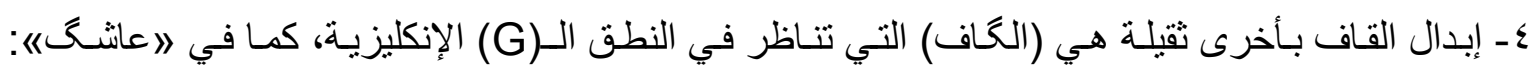

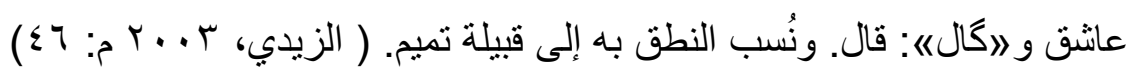

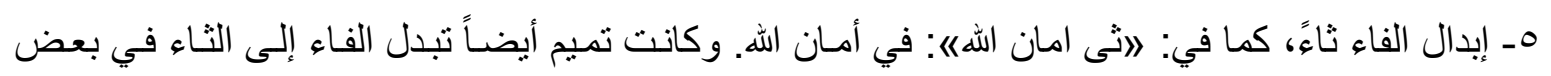

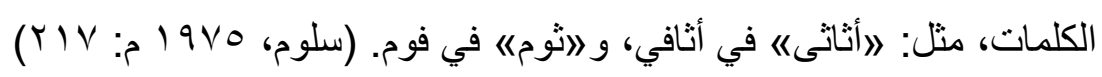
ד- إبدال اللام نوناً، كما في 》إسماعينه: إسماعيل، و 》سنسله|《: سلسله. و إبدال اللام إلى النون كان شـائعاً

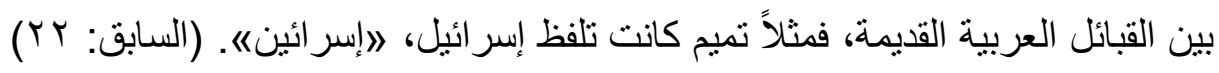
V- ابدال السين إلى الصاد، كقولهم: الصخامه: السخام، و اصلخخه: سلخ. وهذا الابدال ظـاهرة من ظواهر

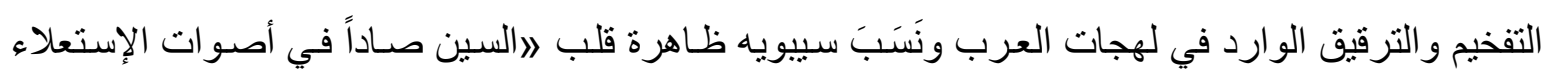
إلى بنـي العنبر و هم مـن بنـي تميم. وأورد ابن جني طائفة من القراءات القر آنيـة على هذا النمطه (ابـن

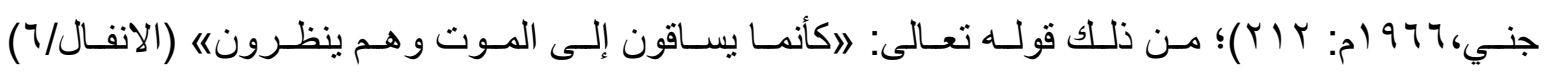

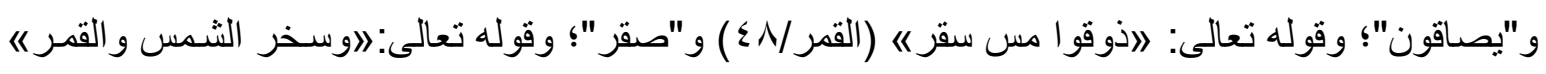

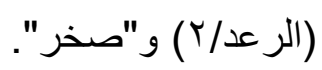

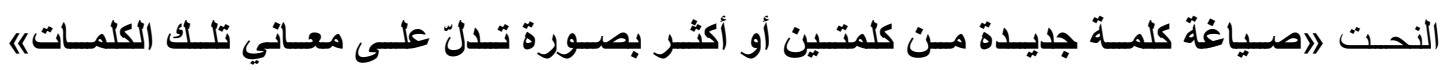

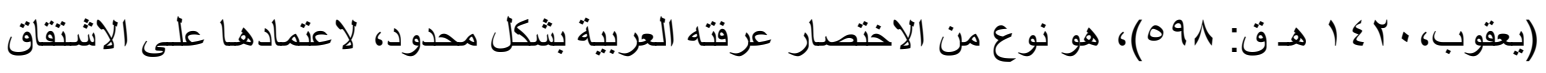

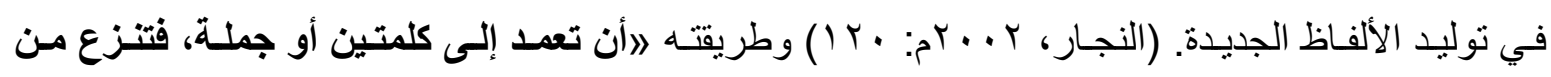

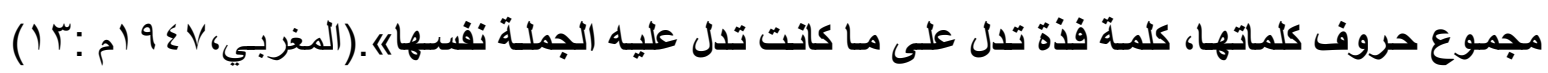
وسبب نشؤه أن المتكلم قد يعسر عليه أن / يفصل بين كلمتين وردتـا الى ذهنـه دفعـة واحدة وربمـا تتداخل 


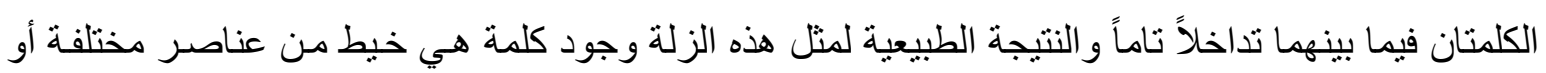

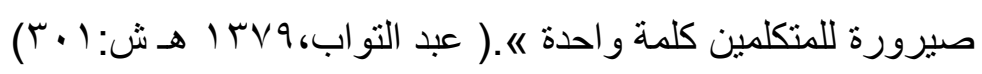

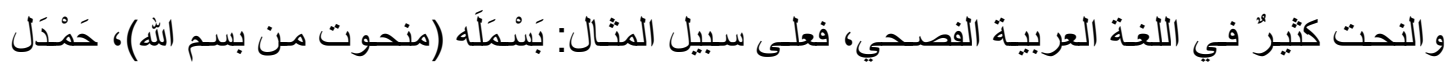

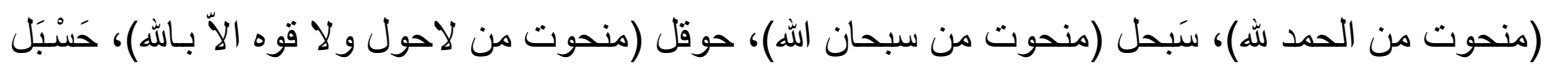

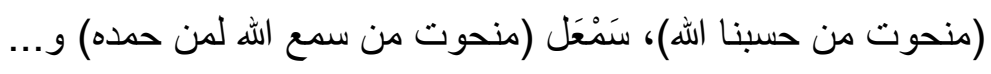

وذهبت اللهجات المعاصرة إلى توليد الألفاظ عن طريق النحت، وقد لاحظنا وسمعنا الكثير من الكلمات

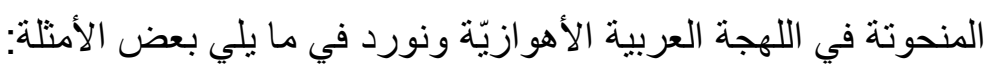

$$
\begin{aligned}
& \text { (الهيّاه): (إلى هذه الساعة) } \\
& \text { 》عليش): (على أي شيء) }
\end{aligned}
$$

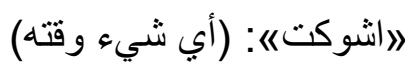

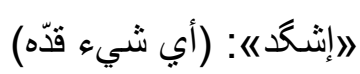

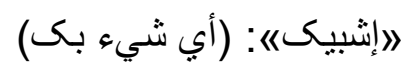

$$
\begin{aligned}
& \text { 》مامش《: (ما مِن شيء) (إيء) }
\end{aligned}
$$

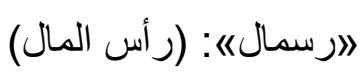

$$
\begin{aligned}
& \text { ״بلاش《: (بلا شي ء) }
\end{aligned}
$$

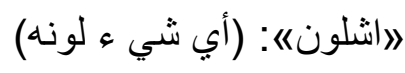

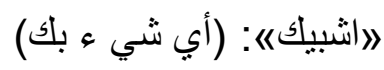

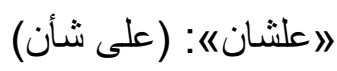

$$
\begin{aligned}
& \text { 》امعليك"): (ما عليك شيء) (عان) } \\
& \text { وهي طريقة من طرق نوليد الألفاظ. }
\end{aligned}
$$

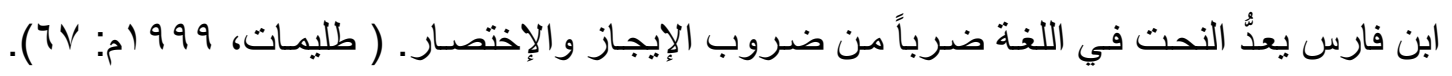

ونعنى به تقديم بعض أصوات الكلمة على بعض، مثل حبذ وجذب؛ وأيس ويسٔ، ويبدو أنه يحدث

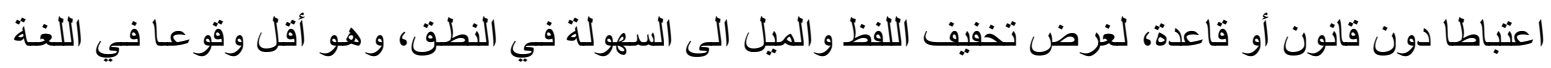

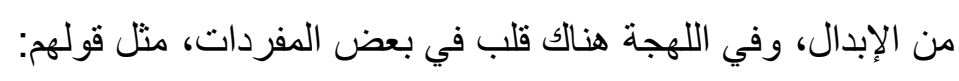

》أيس《؛ في: بئس إنس

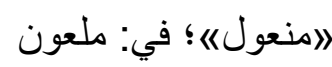

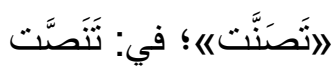

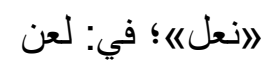

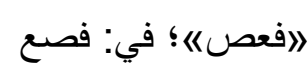

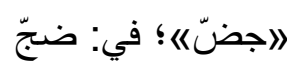




$$
\begin{aligned}
& \text { 》حس《؛ في: سَحَّ } \\
& \text { 》عشطان《؛ في: عطشان } \\
& \text { 》صگد《؛ في: صدگ } \\
& \text { 》حمد《؛ في: مدح } \\
& \text { الإتباع و المز اوجة: }
\end{aligned}
$$

لقد اهتم بهذا الموضوع عدد من علماء اللغة القدامى. وهو موضوع طريف يجمع بين اللغـة والأدب،

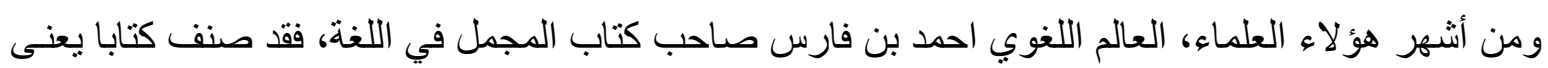
بهذا الموضوع وسمه بـ (الإتباع والمزاوجة ) ذكر فيه مـا ورد في العربية من هذه التعابير المتعلقة بالإتباع و المزاوجة، وفي اللهجة الأهو ازيّة هنالك تعابير كثثرة تدخل ضمن هذا الباب من ذلك:

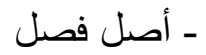

- بطال عطال

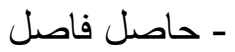

- سالم غانم

- شكو ماكو

- صخام لطام

- عرف ولف - مرف

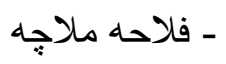

- قارش وارش

- سِيدي كِيدي

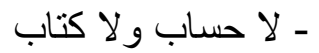

- لا دين و لا يقين

الاتباع هو أن تتبع الكلمة الكلمة على وزنها أو رويها اثباعا وتأكيدا؛ ونقل أبو عبيد في قول الرسول

(ص) 》الثبرم انه حار يار 《) قول الكساني حار من الحرارة ويار اتباع كقولهم عطشان نطشان وحسن بسن و ومثله كثير في الكلام، وإنما سمي اتباعا لأن الكلمة الثانية إنما هي تابعة للأولى على وجـه التأكيد لها وليس

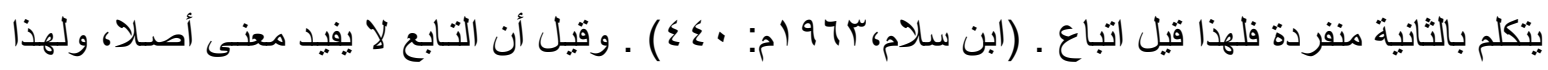

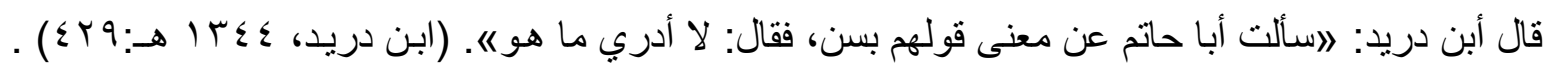

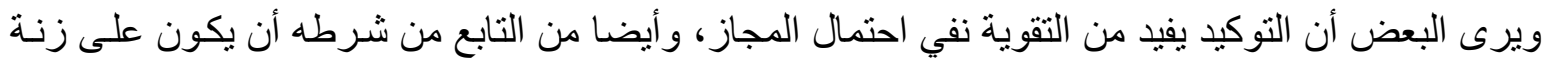

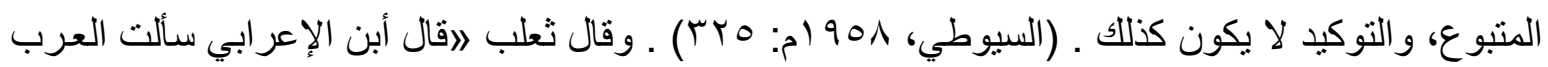

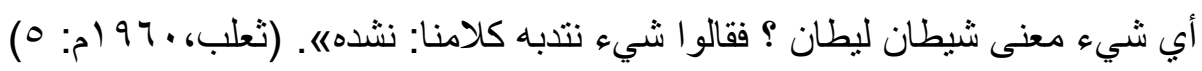

تُنطَق بعض الحروف في اللهجة أحياناً بصورة مفخّمة، ومن هذه الحروف التـي تُنطَق مفذّمـةً، حرف "اللام" كما ينطقه قارئو القرآن في بعض المو اضع، على الأخص إذا جـاء بـالقرب من حرف القاف المقلوبـة 
إلى "الكاف" الفارسية: مكلوب (مقلوب)، و عكل (عقل). و هذا نطق عربي قديم يو افق مثنا احدى قراءت

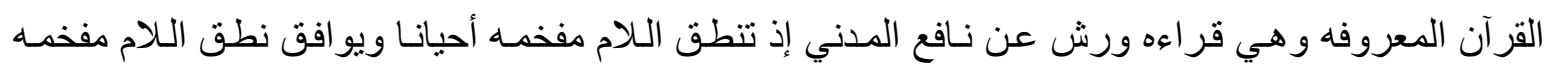
نطق العرب لكلمتي صسلاه وصليب. وهو نطق كما ذكرنـا قديم وفصيح وهو من لهجـات العرب الفصيحه القديمة.

\section{جذور الاهجة في القرآن الكريم:}

لقد أنزل الله القرآن الكريم على سبعة أحرف، وقد قرئ القرآن بسبعة قراءات مناسبة للهجات العربيـة الثائعة آنذاك؛ و اللهجة العربية في الأهو از لاشك إنها منحدرة من هذه اللهجات القديمة التي وردت في القرآن

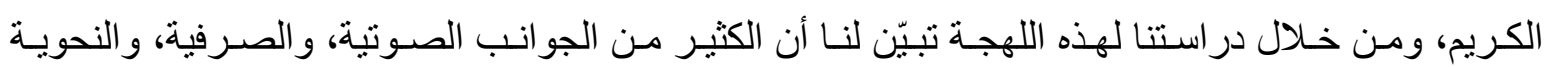
المستخدمة فيها لها صدى عميق في القر آن الكريم.

و هذه اللهجة العربية استطاعت أن تضمّ بين دفتيها آلاف الألفاظ و المفردات و العبار ات الفصحى، ومنها الواردة في القرآن الكريم كقولهم: لابـارت تجـارت فلانه أي كسـت، وبـارت الأرض إذا لم تكن صـالحة

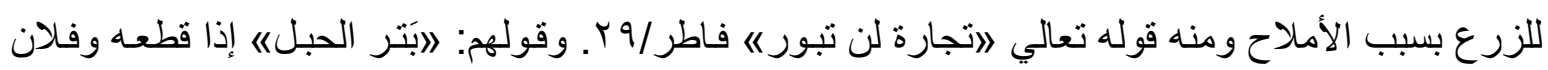

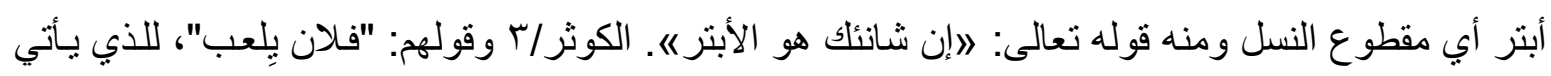
بعمل لا فائدة من فعله.

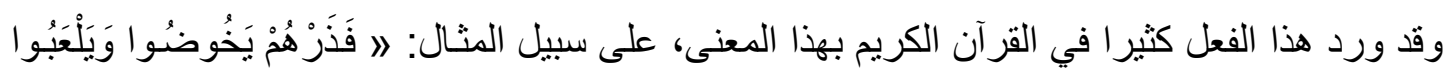

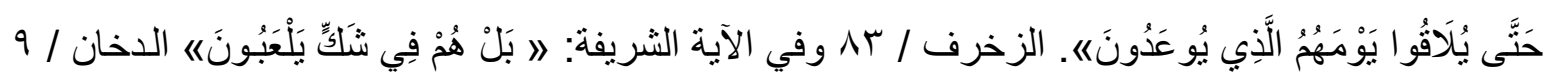

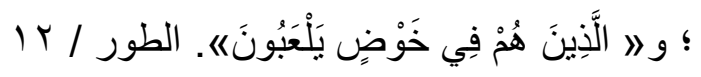

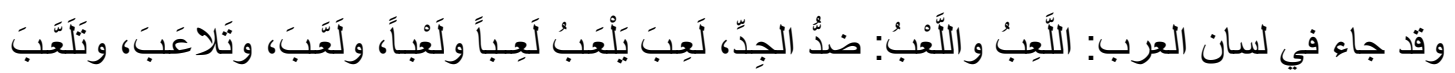

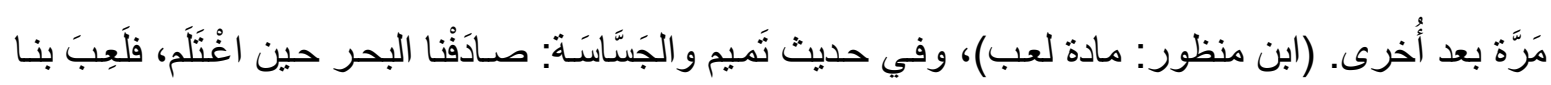

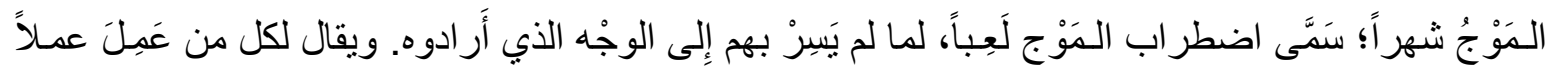

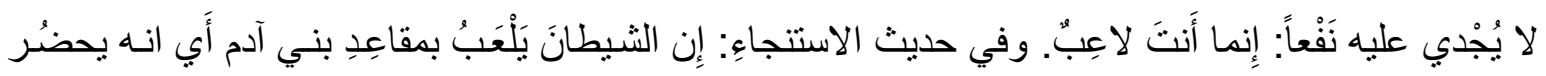

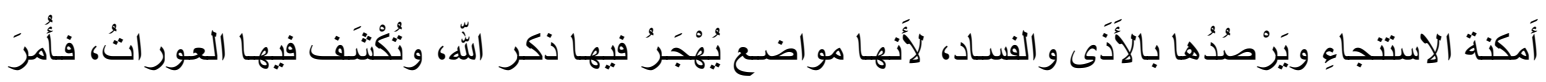

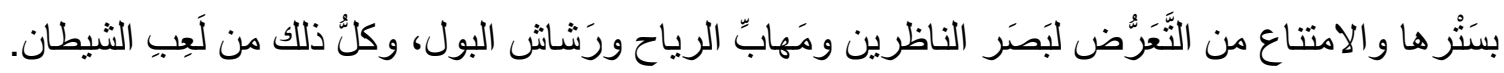

إستعملت نـون التأكيد بكثرة في اللغـة الفصحى، خاصـة في القرآن الكريم والثـعر العربي، أمّا في العصر الحديث فلم نشهـد لها استعمالاً في اللهجات المعاصرة سوى في اللهجة العر اقية واللهجة الأهوازيّة

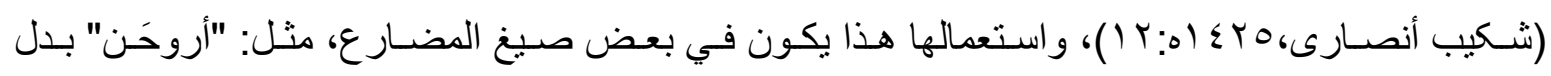

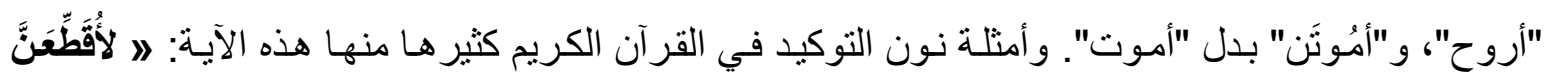

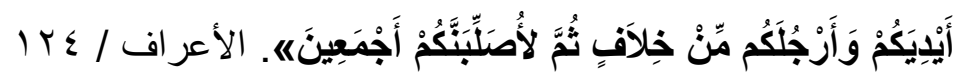




\section{المركات الإعرابية:}

تتسم اللهجات المعاصرة ومنها اللهجـة الأهوازيّة بخلوهـا من العلامـة الإعرابيـة ويميل النـاطقون بهذه اللهجات إلى تسكين أواخر الكلمـات، وظـاهر القول إن العامـة بدأت تتخلص من العلامـة الإعرابيـة منذ وقت

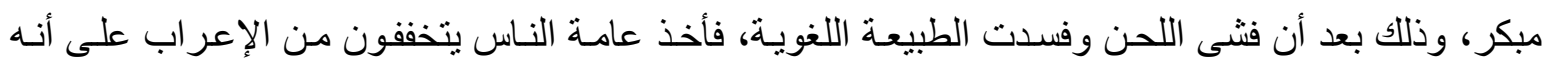
صار ثقيلاً على ألسنتهم بحيث صـار للناس لغة في التخاطب لم يلتزم فيها هذا القيد الذي رأوه ثقيلاً . و وإن إن الوقف على الكلمات العربية بالسكون في كثير من الأحيان، كان من الأمور التي ساعدت على فقدان الإعراب

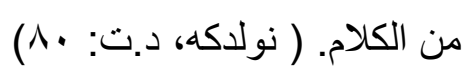

وظاهرة حذف الحركة الإعرابية ليست جديدة في اللغة العربية، بل هي ظاهرة نجدها واضحة في عدد من لهجات العرب القديمة، من ذلك لهجة بني تميم الذين كانو ا بحذفون الحركة الإعرابية طلباً للتخفيف، نحو

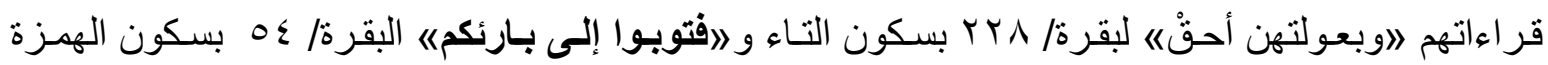
و لاما يشعركمه الأنعام/ 9 ـ ا بسكون الر اء.

يستعمل في اللهجـة العربيـة الأهوازيّة حرفـان من حروف القسم وهمـا: لالو او له و البـاء《. كقولهم:

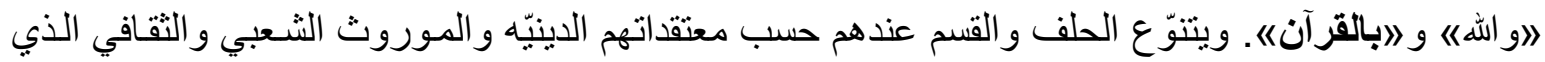
توارثوهُ أباً عن جدّ وخلفاً عن سلف حتى وصل إليهم هكذا. فمن أهمّ أقسـام الحلف أو القسم عندهم: القسم بـاله و القسم بالنبي (ص) و أهل بيته و القسم بالقر آن و القسم بالآباء و الإبناء و القسم بالأوقات و القسم بالثـرف و القسم بأثنياء أخرى.

وقوع (لا) قبل القسم: تقع (لا) قبل فعل القسم وبخاصـة قبل الفعل (أقسم) نحو قولـه تعـالى لافـلا أقسم بالثفقه الانشقاق/ الا ا، وفي القر آن الكريم كلما ذكر فعل القسم (أقسم) جيء بـ (لا) قبله، وقد تأتي (لا) قبل القسم من غير فعل القسم، قال تعالى لافلا وربك لا يؤمنونه. النساء/ ع 7 ويرى النحاة أن ( لا) قبل القسم زائدة تفيد التوكيد. (الرازي، إبـ ا هـ: بـ ( )، وفي اللهجة الأهوازيّة تقع (لا) قبل القسم، و هي زائدة تفيد التوكيد، نحو قولهم "لا و الله مـاسمعت أي شيء"، وكذللك تفيد الرد على قول سابق لغرض تكذيبه نحو قوللك: "لا و الحسين ما كلت".

\section{الامطابقة التركيبية (التصريج بالفاعل بعد واو البماعة):}

سلكت اللهجة مسلك اللغة العربية الفصحى، في المطابقه بين المسند و المسندإليه، والصفة والموصوف، و الحال وصاحبه، و إسم الإشاره و المشار إليه في: 》التذكير و التأنيثه و 》الإفر اد و الجمعه وخالفتها في: 1:

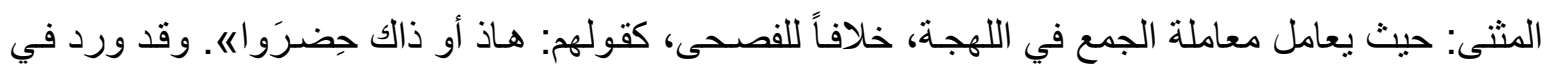

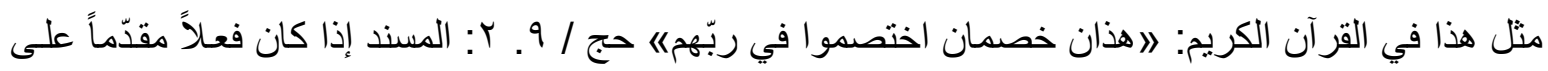

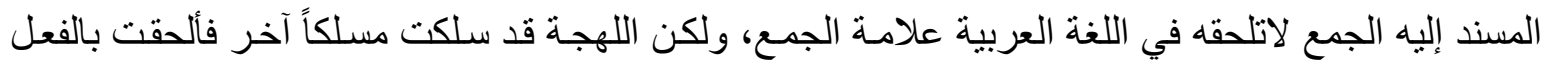

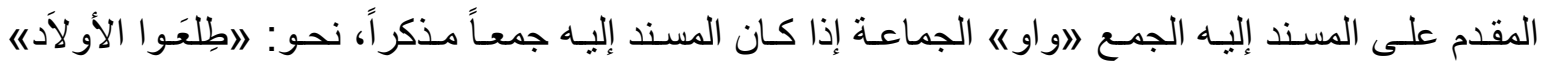




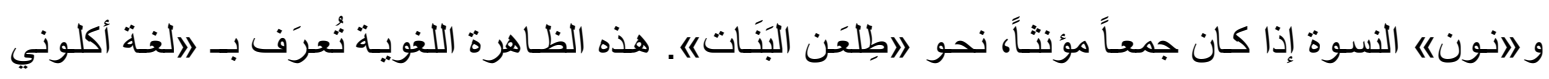

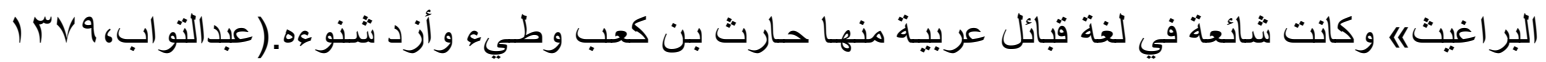

هـ ش: (Y)

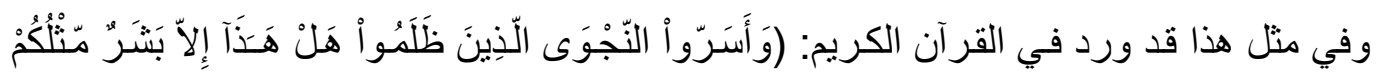

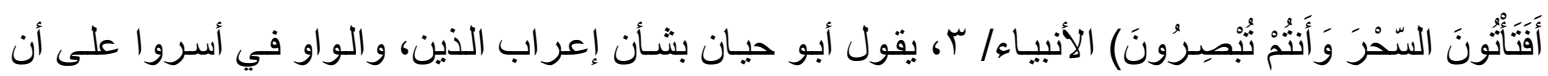
الذين: لافاعل و الواو فى أسروا علامة للجمع على لغة أكلونى البر اغيث قاله أبو عبيدة و الأخفش وغير هما

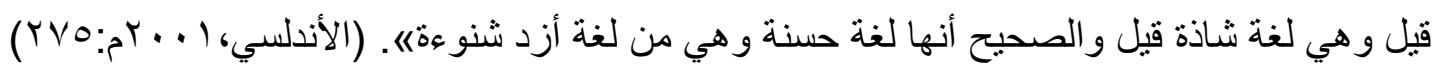
أود أن أثنير إلى أنه إن كان أبو حيان قد أثـار إلى كون تلك اللهجة شـاذة، فقد أثشار الراجحي إلى أن: اهذه القر اءات تدل ـ بما لا يدع مجالا للشك ـ أن هذه اللهجة كانت معروفة ومعترفا بها فى الفصحى، وقد إند

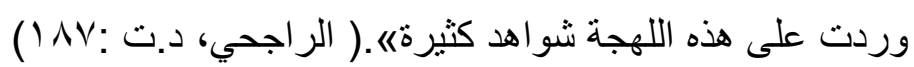

\section{تهقيق الهمهزة:}

في الأهواز يحقّقون الهززة في كلامهم أي يقلبون هذا الحرف أحياناً إلى أقرب حرف من حروف العلة، فيقولون "راس" في "رأس"، و"بير" في "بئر"؛ و هذه الظاهرة كانت شائعة بين القبائل العربية القديمة. النطق بـالهمزة من الظواهر التى اثتركت فيها قبيلـة أسـد مـع غيرهـا من القبائلـ، حيث اختلفوا

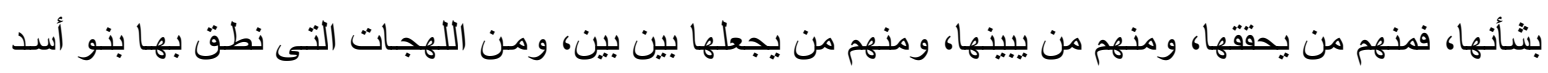

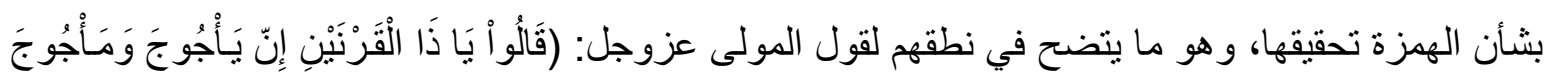

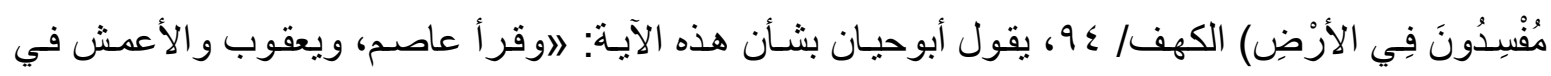

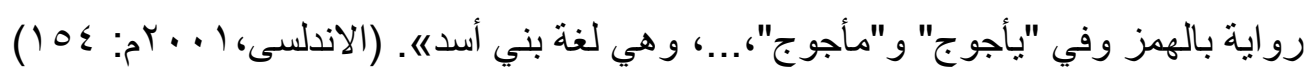
وقد وجه علماء القراءات القر اءة الواردة في اللفظتين المذكورتين، كذلك من الناحيـة الصـرفية، يقول ابن مجاهد: لاو اختلفوا في همز يأجوج ومأجوج فقر أ عاصم وحده يأجوج ومـأجوج مهموزين وقرا الباقون

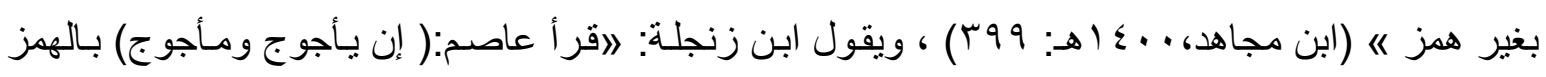

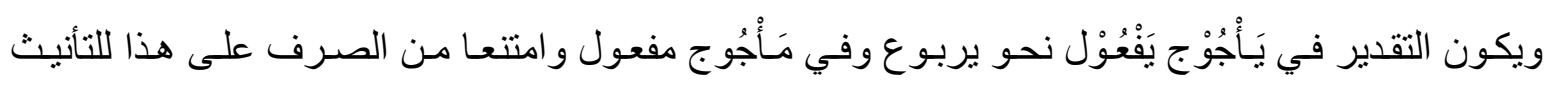
و التعريف كأنه اسم القبيلة وقر أ الباقون يَاجُوج وماجوج. يـاجوج فاعول ومـاجوج فاعول أيضـاه (ابن زنجلة

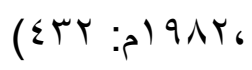

أجمع كثير من العلماء على أن تحقيق الهمزة يختص بنطقها سـاكنو البادية من القبائل العربيـة مثل

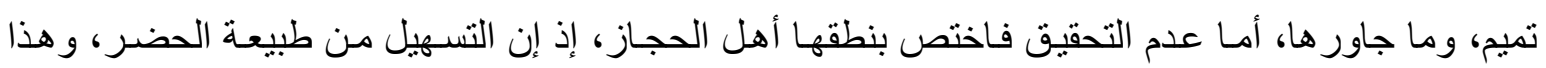
التعود الصـوتي لم يألفه جميع أهل الحجاز ،لا إذ ليس معنى ذلك أن قبائل الحجـاز كلها كانت تتخلص من الهمز / (الر اجحي، د.ت : 7 ـ ـ ()، وهذا ما يتضح في نطقهم للهمزة محققة في لفظة "الذئب"من خلال قوله ـ

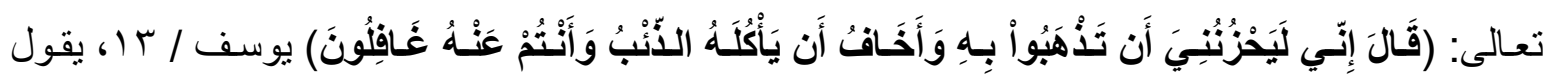

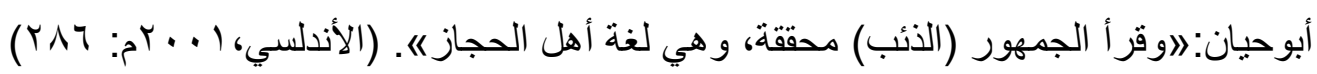


وقد انفردت بعض القبائل البدوية بتحقيقها أحياناً، والإغراق فيه بقلبها عيناً يسلكون في ذلك مسلك بني تميم الذين يقلبونها عيناً أحيانًا مبالغة في تحقيقها، وقد أثِر عنهم هذه القر اءة: (إذا جـاءك المنافقون قالوا نشـهـ عنَّك لرسول الله)، ومازلنا نسمع كثيرًا من أهل الباديـة يقولون: (اسعلك سْعال)، أي (أريد أن أسـألك سؤالاً). و لا زالت اللهجة الأهوازيّة تحتفظ بعدد من الكلمـات التي حققت فيها الههزة إلى حد الإغراق فقلبت عينـاً

$$
\text { وتعرف هذه الظاهرة بـ (العنعنة). }
$$

و هنالك من يزيد في تسهيل الهمزة من الكلمات التي يجري تحقيقها في لهجـة الحاضرة ومـا شـاكلها كما هو الحال على سبيل المثال مع الصفات والعاهات التي جاءت على وزن أفعل فيقولون: (عمي، وعري)

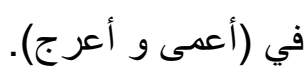

وأما الألوان فلم يؤثر تسهيل الهمزة منها سوى في (أخضر، وأحمر)، فيقولون: (خضر، وحمر). و لا يقولون في بقية الألوان: (زرگ، وصفر، وسود، وبرگ)، بـل يقولون: (أزرگ، وأصفر، و وأسود، وأبرگ)،

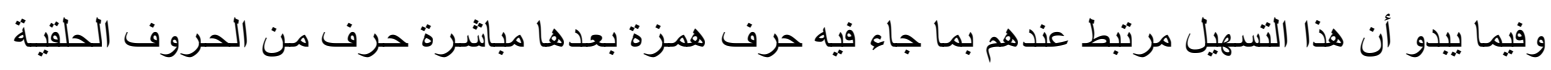
كالحاء، أو الخـاء، أو العين، و الهاء، ولعل هذا الحذف أو التسـهيل هو كراهـة منهم لاجتمـاع حرفين حلقين متجاورين لنقلهما عندهم في المخرج، وفي تسهيل أحدهما وهو الأول تسهيل على اللسان في النطق.

\section{الحاق هاء السكت بعد ياء المتكلم للاقوف عليها:}

تسود هذه الظاهرة في اللهجة، فيقولون: (بُويِه، وخُوِِه) والأصل: أبي، وأخي؛ وهم يسكنون الحرف السابق لياء المتكلم لاستثقالهم الكسرة حركته الأصلية.. وتكثر هذه الهاء في ربّاط الأبوذية كما في البيت التالي وهي ولي للشاعر حسن عاشتور:

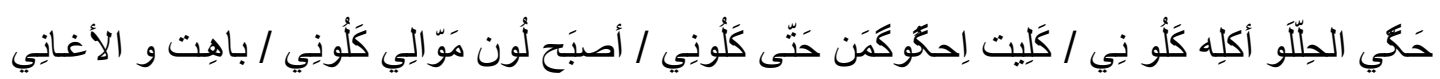
إنطِفَت بيّهـ

شرح البيت: أكلوا حقّي وسلبوه بعد أن حلّلوه على أنفسهم / أنا من قبل هذا أكلتُ حقّ من، حتى هكذا يسلبوني حقي؟ / لقد أصبح لون شعري بمثابة الموال (وهو لون من الشعر العامي) / باهنتاً، فقد انطفئت فيـه الأفر اح و الأغاني.

و الأصل "بـي" بـدل "بيـه" في هذا الربّاط، ولو نتبعت أبيـات الأبوذيـة لوجدت أن الكلمـة الأخيرة من

خاتمتها تنتهي بهاء سكت حقيقية أو تاء تأنيث مربوطة فصارت هاءً مماتلة لهاء السكت عند الوقوف عليها.

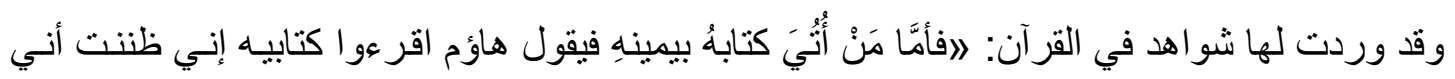

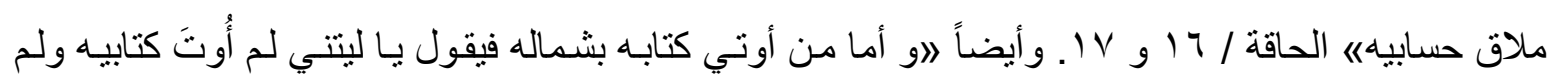

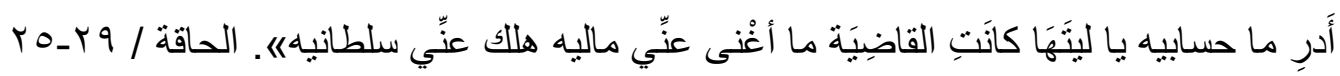

$$
\text { وفي الآية التالية: (وما أدريك ماهيه). القارعة / • }
$$

إن الأصل في هذه الألفاظ: (كتابي، وحسابي، ومالي، وسلطاني، وماهي)، فلما أضيفت لها هـاء السكت أضافت إليها حسناً زائداً على حسنها، وأكسبتها لطافة ولباقة. 
استعمال الفعل الثلاثي المزيد بالهمزة بدلا من الثلاثي المجرد:

من الظوا اهر الصـرفية الملحوظـة عندهم استعمالهم الفعل الثلاثي المزيد بـالهمزة بـدل الفعل الثلاثي

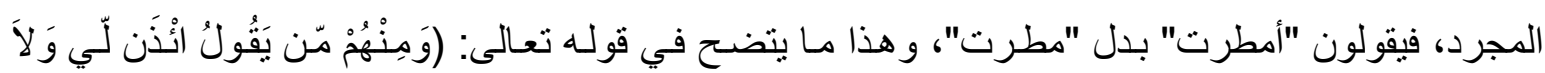

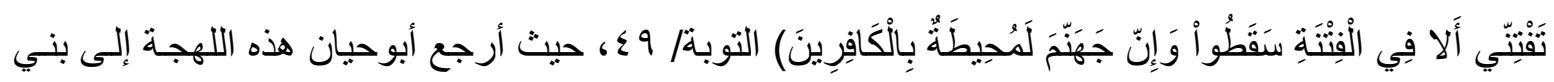

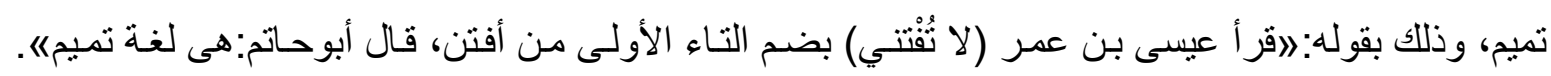

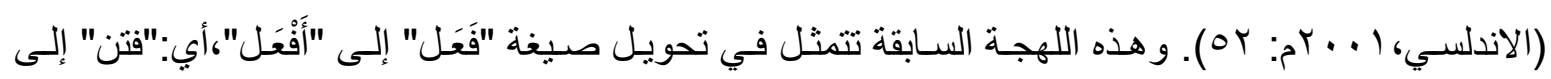

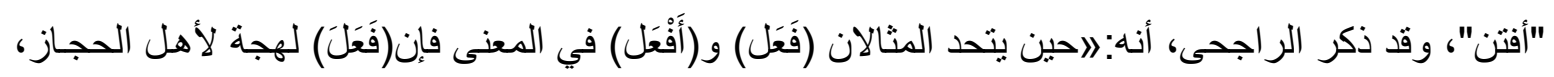

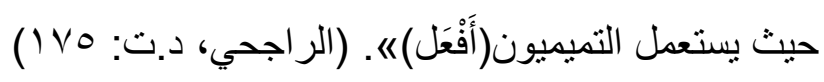

\section{كسر حرف الاضارعة هن الفعل الاضارع (ظاهرة التلتلة):}

ومن الظو اهر اللهجية التي تجد لها نظيرا في سلوكهم الحديث مـا يسمى (بالتلتلة)، وهي تعني كسر

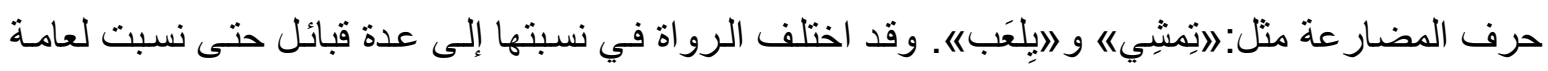
العرب، كما اختلفوا في تحديد الحرف المكسور، فهل هو التاء فحسب، كما يقال: (تعلمون) أو هو التاء والنون كما يقال: (نستعين)؟ أو هو كل أحرف المضار عة؟ روايات مختلفة، ولكن السلوك المعاصر لبعض اللهجات الحديثة يشهد لهذا المسلك اللهجي في ثناثتة من أحرف المضـار عة، فيقولون: (تِكدر، نِلِعب، بِلعب)، فُتكسر

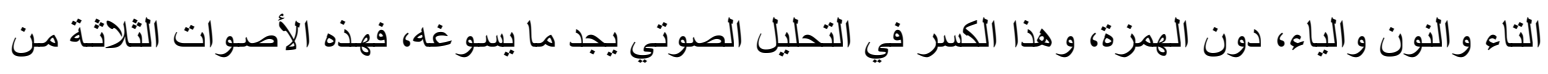

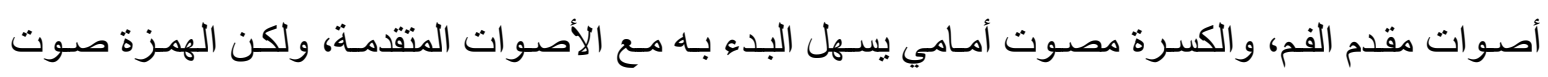

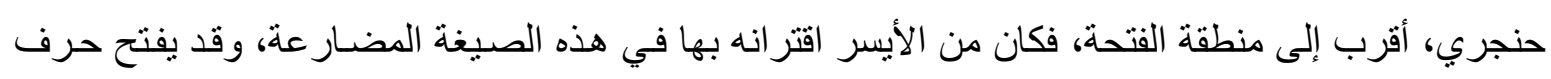

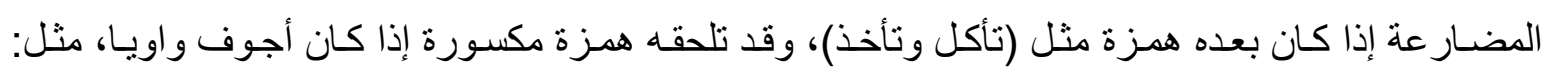

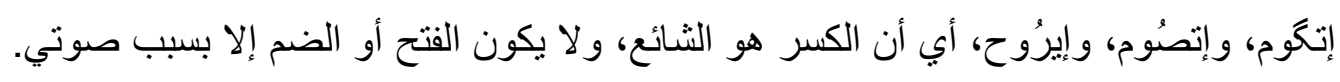

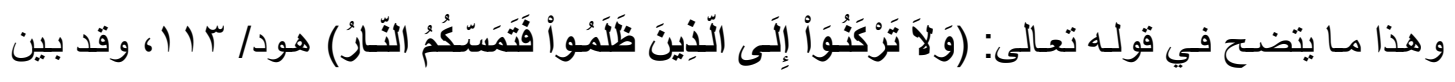

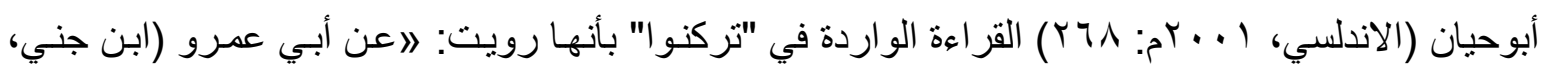

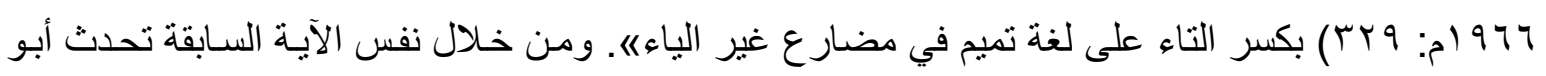

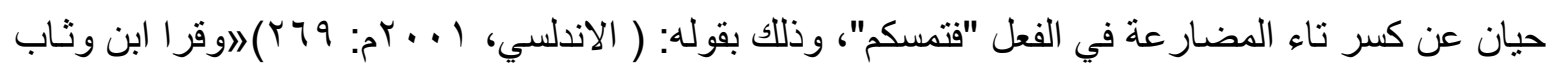

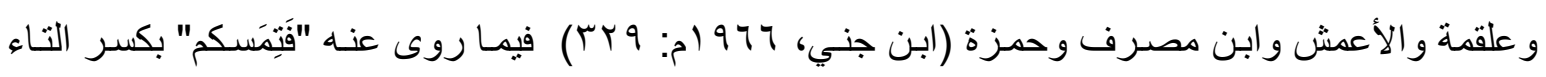
على لغة تميمها. و عن كسر أحرف المضار عة عقد سيبويه بابا أطلق عليه: ابـاب مـا تكسر فيه أوائل الأفعال

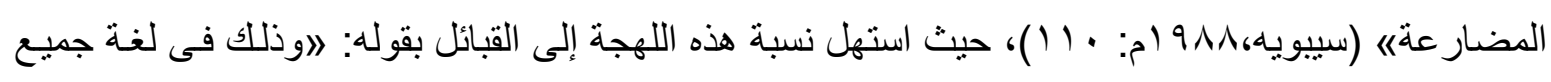

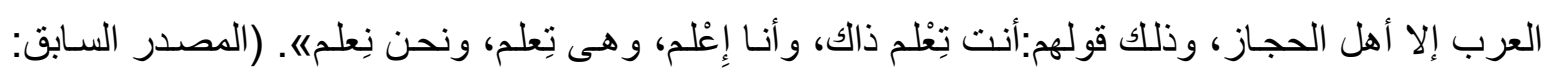

وقد وجه ابن جني كسر التاء في الفعل من الناحية اللغوية بقوله: إقال أبو الفتح: هذه لغة تميج،أن تكسر

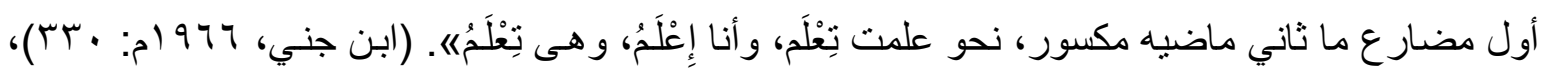

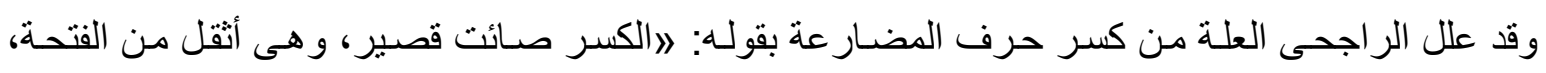


و أخف من الضمة، والمعروف أن حرف المضار عة يحرك بالقتحة إلا إذا كان الماضي رباعيا فإنه يضم، لكن بعض القبائل كانت تجنح إلى تحريك حرف المضار عة بالكسرة دائماه، (الراجحي، د.ت: ع (1) (1).

\section{قراءة الأهمر على صيغة الماضي:}

ورد عنهم قر اعة الأمـر بصـيغة الماضـي وقد تمثل هذا في الأفعـال المهموزة المتمثلـة في: اسـأل،

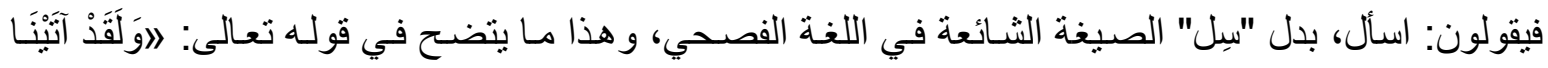

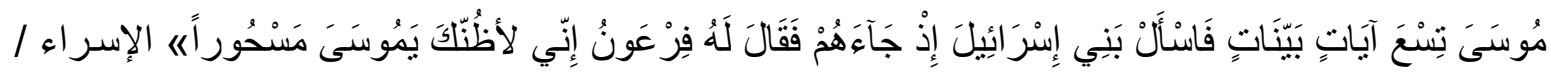

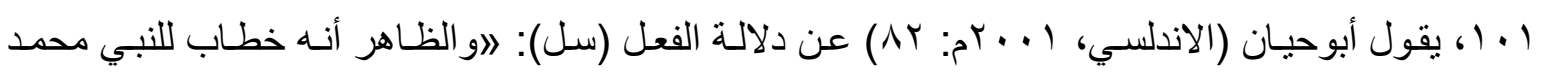
(ص)، أمره أن يسألهم عما أعلمه به من غيب القصةها. ولما كان السؤال من باب الأمر من المولى عزوجل

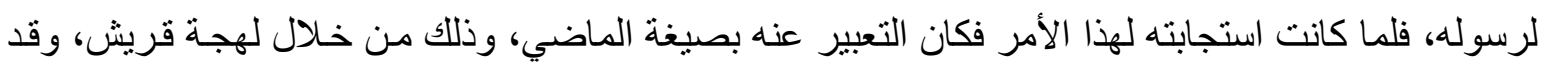
تحدث الزمخشري (الكثاف، /9/9/7) عن اللفظة المذكورة بقوله: /اسلهم عن إيمانهم و عن حال دينهم، أو سلهم أن يعاضدوك وتكون قلوبهم وأيديهم معك. وتدل عليه قر اءة رسول الله (ص): فسأل بني إسر ائيل على ونى لفظ الماضي بغير همز وهي لغة قريشه.

\section{حذف نون المثنى عند الإضافة:}

من الظواهر اللغويـة في لهجـة الأهواز حذفهم لنون المثنى أحيانـاً عند إضـافتها، وهذا مـا يتضـح في نطقهم (رحم الله والديك) بدل "و الدينك". وحذف هذه النون في القرآن الكريم كثير عند الإضافة، كما جاء في

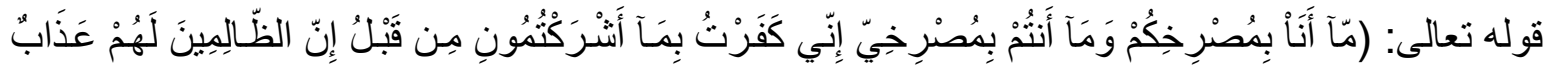

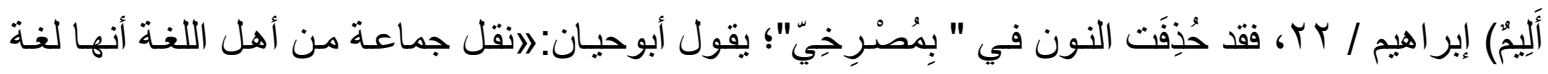

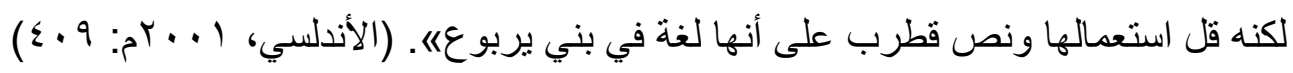

لكلّ لغةٍ لهجات قد تفرّ عت عنها حسب العو امل الجغر افية والإجتماعية و الثقافية، فاللغنة العربيـة إحدى اللغات السامية التي إنتقِت منها لهجات مختلفه، ومن هذه اللهجات، اللهجة العربية في الأهواز التي تضربه

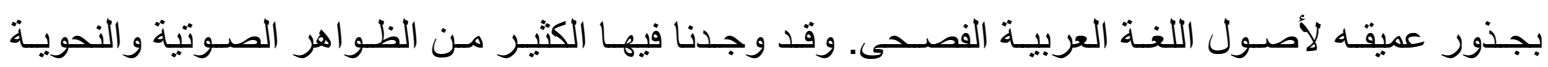
و الصرفية تقترب للغة الفصحى، وما هذا إلّا خير شاهدٍ على فصاحتها وإصالتها و إنحدار ها للغة العربية. وقد تعرّفنا في هذه الدراسة على بعض الظواهر في اللهجة العربيـة الأهو ازيّةـة. فوجدنا هذه اللهجة قد خضعت إلى النظـام اللغوي الذي يحكم اللغـة العربيـة الموحدة، كمـا إنّها خضـعت إلى الكثير من الظواهر الصوتية المتجذّرة في القرآن الكريم كتفخيم بعض الحروف كحرف "اللام" كما ينطقه قارئو القرآن الكريم

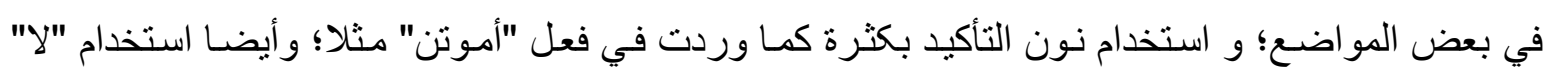
القسم الز ائدة كما وردت كثيرا في القرآن؛ وتحقيق الهمزة؛ والحاق هاء السكت بعد ياء المتكلم للوقوف عليها؛

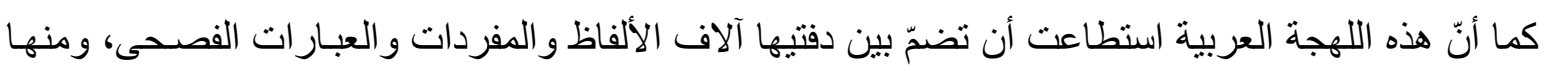
الواردة في القرآن الكريم كقولهم: لابارت تجارت فلانه أي كسدت. 
اــ الأبوذية نوعُ من الثُعر العامي يشبه "الدوبيتي" الفارسي. تتكوّن الأبوذية من أربعة أشطر ؛ الثناثة الأولي تُختَم بالجناس التام والثطر الأخير ينتهي بمفردة آخرها "يه".

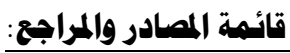

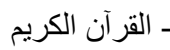

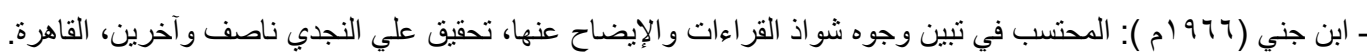

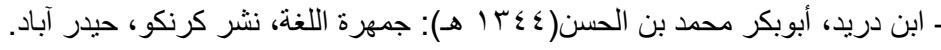

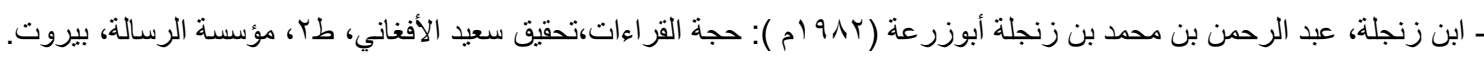

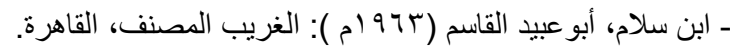

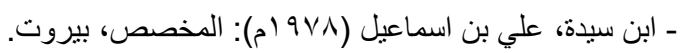

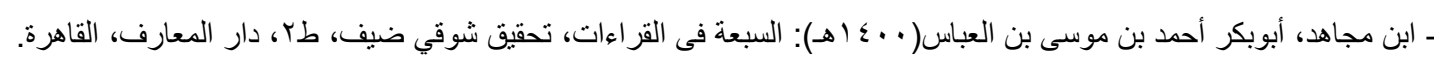

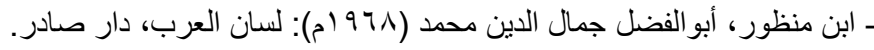

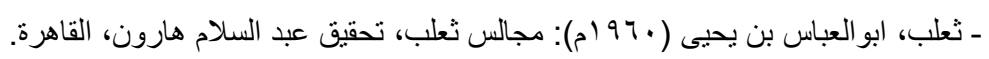
- ابو الفرج، محمد احمد (1990 م): مقدمة لدراسة فقة اللغة، بيروت.

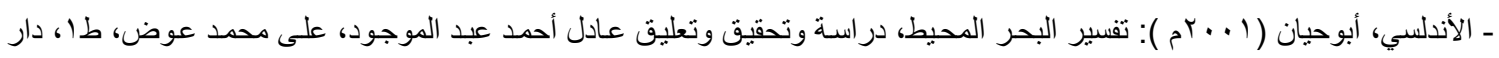

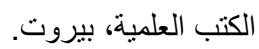

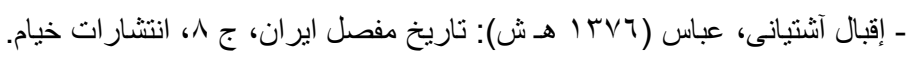

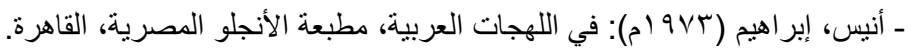

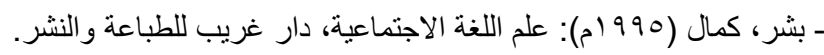

ـ ـ الراجي، عبده (د.ت): اللهجات العربية في القراءات القر آنية، دار المعرفة الجامعية، الإسكندرية.

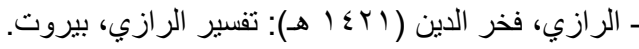

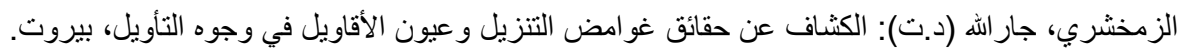

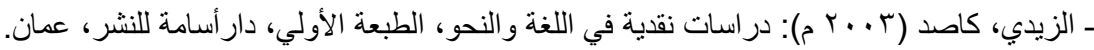

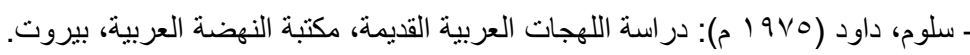

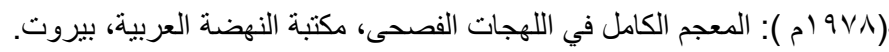

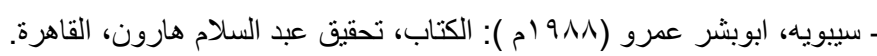

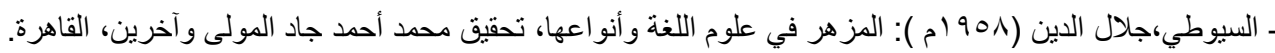

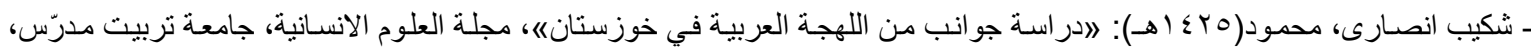

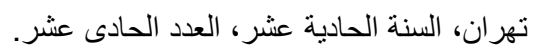

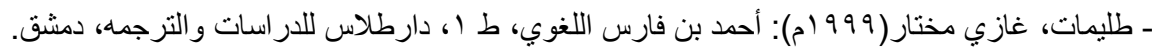

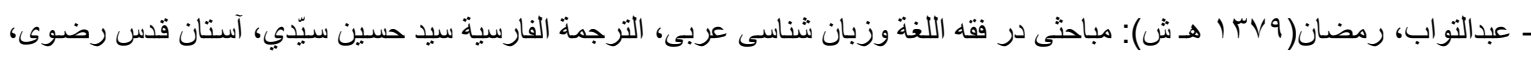

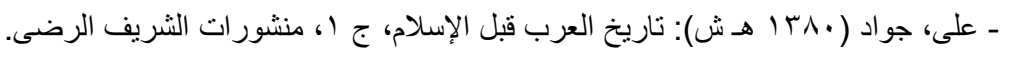

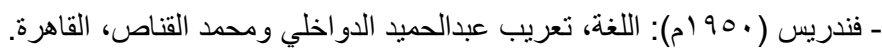

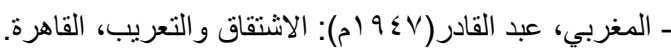

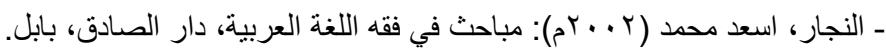

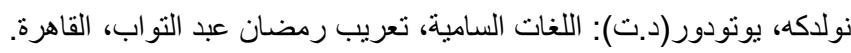

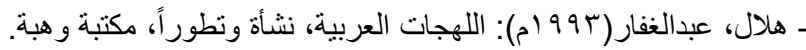

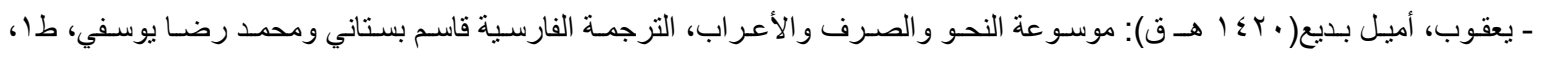

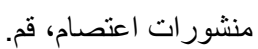

